\title{
Influência de variáveis ambientais em ambientes lóticos de Mata de Araucária sobre a taxocenose de Odonata
}

O tamanho dos corpos d'água pode ser considerado o principal controlador das características físicas e químicas dos ambientes lóticos. Portanto, o tipo de substrato, a vazão, a composição orgânica e inorgânica e heterogeneidade de habitat possuem relação direta com a dimensão do ambiente lótico. Por sua vez essas características são determinantes na distribuição e diversidade da fauna de imaturos de Odonata. Neste contexto, testamos a hipótese de que diferentes dimensões de ambientes lóticos sustentam diversidade similar de imaturos de Odonata, entretanto, diferem quanto a sua composição. Assim, avaliamos a influência do tamanho do corpo d'água sobre fatores abióticos e estrutura da taxocenose de imaturos de Odonata. Realizamos cinco amostragens sazonais entre 2011 e 2012, no Parque Nacional das Araucárias, Santa Catarina, em oito ambientes, através de métodos quantitativos e qualitativos. Foram registrados 520 indivíduos de Odonata, distribuídas em oito famílias e 41 gêneros. Os ambientes foram evidentemente separados pela classificação dos rios. Os maiores valores de diversidade, riqueza e equitabilidade foram registrados nos córregos pequenos, ambientes com maior heterogeneidade de habitat, maior porcentagem de matéria orgânica e protegidos pela mata ciliar. Confirmou-se com esse estudo que a alta heterogeneidade de habitat em ambientes lóticos de baixas ordens influencia na diversidade, abundância e riqueza da fauna de Odonata. Outro fator determinante para os altos índices foi à integridade do local de estudo, favorecendo a proteção e ciclagem de nutrientes nos corpos d'água.

Palavras-chave: Insetos; Córregos Pequenos; Zona Ripária; Heterogeneidade de Habitats; Parque Nacional das Araucárias.

\section{Influence of environmental variables in Araucaria Forest lotic environments on taxoncenosis of Odonata}

\begin{abstract}
The size of the water bodies can be considered the main controller of the physical and chemical characteristics of the lotic environments. Therefore, the substrate type, river flow, organic and inorganic composition, and habitat heterogeneity are directly related to the size of the lotic environment. In turn, these characteristics are determinant in the distribution and diversity of the immature fauna of Odonata. In this context, we test the hypothesis that different dimensions of lotic environments support similar diversity of Odonata immatures, however, differ in their composition. Thus, we evaluated the influence of water body size on abiotic factors and Odonata immature body taxocenosis. We carried out five seasonal samplings between 2011 and 2012, in the Araucarias National Park, Santa Catarina, in eight environments, through quantitative and qualitative methods. There were 520 Odonata individuals, distributed in eight families and 41 genera. The environments were evidently separated by the classification of the rivers. The highest values of diversity, richness and equitability were recorded in small streams, environments with greater habitat heterogeneity, higher percentage of organic matter and protected by ciliary forest. It was confirmed by this study that the high habitat heterogeneity in low order on lotic environments influences the diversity, the abundance and the richness of the Odonata fauna. Another determining factor for the high indexes was the integrity of the study site, favoring the protection and cycling of nutrients in water bodies.
\end{abstract}

Keywords: Insects; Small Stream; Riparian Zone; Environments Heterogeneity; Araucarias National Park.

Topic: Desenvolvimento, Sustentabilidade e Meio Ambiente

Reviewed anonymously in the process of blind peer.

Bruna Laís Turra

Universidade Comunitária da Região de Chapecó, Brasil

http://lattes.cnpq.br/2922012720373385

bruninha.lais@gmail.com

Erikcsen Augusto Raimundi (iD

Universidade Federal do Espírito Santo, Brasil

http://lattes.cnpq.br/6301544487780423

http://orcid.org/0000-0002-3539-2062

erikcmundi@gmail.com

Gilza Maria de Souza-Franco (id

Universidade Federal da Fronteira Sul, Brasil

http://lattes.cnpq.br/4018616229163111

http://orcid.org/0000-0002-5023-3211

gilza.biologa@gmail.com

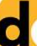

DOI: $10.6008 / C B P C 2179-6858.2018 .003 .0023$
Received: 10/02/2018

Approved: 24/03/2018
Referencing this:

TURRA, B. L.; RAIMUNDI, E. A.; SOUZA-FRANCO, G. M.. Influência de variáveis ambientais em ambientes lóticos de Mata de Araucária sobre a taxocenose de Odonata. Revista Ibero Americana de Ciências Ambientais, v.9, n.3, p.289-305, 2018. DOI:

http://doi.org/10.6008/CBPC2179-6858.2018.003.0023 


\section{INTRODUÇÃO}

Informações sobre padrões de distribuição e de abundância das espécies são relevantes pois tornam mais efetivos os esforços para a conservação de fragmentos florestais (LEWIS, 2006). Tal afirmação, por sua vez, também é válida para os invertebrados bentônicos, pois esses padrões são determinados por um grande número de variáveis ambientais que atuam conjuntamente (ASSIS et al., 2004). Dentre as principais variáveis estão a concentração de oxigênio dissolvido (ESTEVES, 2011), a temperatura da água (MERRIT et al., 1996), o clima e o pluviosidade (ALLAN, 1995), o pH e a correnteza e a vazão (WARD, 1992). A presença de vegetação ciliar, a quantidade de luz e a largura do ambiente aquático (SILVA et al., 2010), além da disponibilidade e qualidade do alimento e tipo de sedimento (orgânico, arenoso, argiloso, etc.) (MINSHALL, 1984; ASSIS et al., 2004; ESTEVES, 2011) também são características que influenciam a distribuição desses invertebrados (HYNES, 1970; TOWNSED, 1989; FERREIRA-PERUQUETTI et al., 2002), sendo que em ambientes heterogêneos há maior diversidade de nichos ecológicos (CALLISTO et al., 2004).

Nesse sentido, a teoria do contínuo fluvial - River Continuum Concept (RCC) - formulada por Vannote et al. (1980) prediz que a distribuição das guildas tróficas estaria diretamente ligada aos fatores citados anteriormente. Essas interações devem variar sistematicamente de riachos de cabeceiras para rios menores. Ainda, Vannote et al. (1980) argumentam que, em rios sob condições naturais, a distribuição logitudinal da riqueza de espécies acompanha uma curva normal com o pico ocorrendo no trecho médio do rio. Porém, estudos sobre padrões de distribuição espaciais e temporais para rios de clima tropical apontam resultados conflitantes, afastando-se parcialmente de algumas predições do RCC (BAPTISTA et al., 1998). Para Satzner et al. (1985) as ordens dos rios não representam uma descrição confiável da complexidade do ambiente físico, não explicando significativamente a variação da composição faunística. Para Baptista et al., (1998), a similaridade entre as faunas está mais associada ao tipo de substrato do que à ordem do rio.

As larvas de Odonata são exclusivamente predadoras (CUMMINS, 1973), utilizando como alimentos tecido animal vivo (CUMMINS et al., 1979). Os predadores seriam os menos representativos, ocorrendo onde há presas, mantendo a mesma proporção de biomassa ao longo do contínuo alterando-se pouco em relação a dominância nos riachos de diferentes ordens, ou seja, não é influenciada pelo aumento dos riachos no sentido cabeceira - foz devido à manutenção da disponibilidade de presas (VANNOTE et al., 1980). As principais predições para essa ordem são que a riqueza de espécies diminui ao longo do rio (MARCO et al., 2002).

A partir desses pressupostos, testamos a hipótese de que diferentes dimensões de ambientes lóticos sustentam diversidade similar de imaturos de Odonata, entretanto, diferem quanto a sua composição. Assim, avaliamos a influência do tamanho do corpo d'água sobre fatores abióticos e estrutura da taxocenose de imaturos de Odonata ao longo de diferentes sistemas lóticos.

\section{MATERIAIS E MÉTODOS}

\section{Local de estudo}


Realizamos o estudo no Parque Nacional das Araucárias (PNA; Figura 1), localizado entre os municípios de Ponte Serrada e Passos Maia, no estado de Santa Catarina. O PNA possui cerca de 13.000 hectares e fitofisionomia de Floresta Ombrófila Mista. Importantes rios formam a hidrografia no PNA, como os rios Chapecó, Chapecozinho e rio do Mato; todos pertencentes à Bacia Hidrográfica do Rio Chapecó (BHRC). A mata ciliar nos ambientes amostrados encontra-se em diferentes estágios de conservação, desde ambientes bem conservados (interior de mata), em fase de regeneração, e com cultivo de plantas exóticas (Tabela 1).

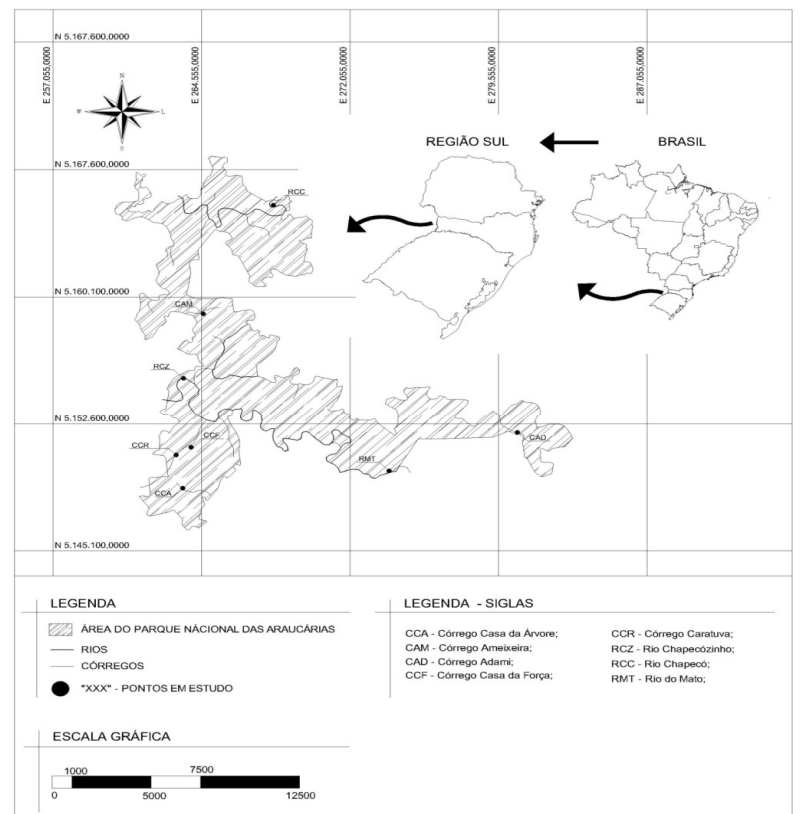

Figura 1: Localização geográfica do Parque Nacional das Araucárias (PNA) em Santa Catarina, Brasil e ambientes amostrados.

Coletamos trimestralmente, de 2011 a 2012, em oito ambientes lóticos de diferentes tamanhos. Para a classificação destes ambientes utilizamos as características dos corpos d'água, de acordo com Meybeck et al. (1996). Assim, os classificamos em: a) córregos pequenos - CoPe: córrego Caratuva (CCR), córrego Casa da Árvore (CCA), córrego Ameixeira (CAM) e córrego Adami (CAD); b) córrego, o qual citamos como córrego intermediário - Coln: córrego Casa de Força (CCF); e c) rios pequenos, os quais citamos como córregos grandes - CoGa: rio Chapecozinho (RCZ), rio Chapecó (RCC) e rio do Mato (RMT) (Figura 1).

Tabela 1: Principais características dos ambientes utilizados para as coletas de imaturos de Odonata, no Parque Nacional das Araucárias (PNA), durante o período de 2011 a 2012. CCR: córrego Caratuva; CCA: córrego Casa da Árvore; CAM: córrego Ameixeira; CAD: córrego Adami; CCF: córrego Casa de Força RCZ: rio Chapecozinho; RCC: rio Chapecó; RMT: rio do Mato; CoPe: córrego Pequeno; Co: córrego; CoGa: córrego grande; Se: seixos; Fo: folhiço; Ar: areia; La: lama; Ma: macrófitas; $\mathrm{n} / \mathrm{m}$ : não medido.

\begin{tabular}{|l|l|l|l|l|l|l|l|l|}
\hline & $\begin{array}{l}\text { Coord. } \\
\text { geográfica }\end{array}$ & $\begin{array}{l}\text { Alt. } \\
(\mathbf{m})\end{array}$ & Categ. & $\begin{array}{l}\text { Corrent. } \\
\left(\mathbf{m} / \mathbf{s}^{-1}\right)\end{array}$ & $\begin{array}{l}\text { Largura } \\
(\mathbf{m})\end{array}$ & $\begin{array}{l}\text { Profund. } \\
\text { média }(\mathbf{m})\end{array}$ & Substrato & Vegetação \\
\hline CCR & $\begin{array}{l}\text { S: 26 49' } \\
22.21251^{\prime \prime} \\
\text { W: } 51 \text { 59' } \\
23.49326^{\prime \prime}\end{array}$ & 995 & CoPe & 10,85 & 2 & 0,4 & Se/Fo/Ar/La & $\begin{array}{l}\text { Área semiaberta } \\
\text { com mata ciliar do } \\
\text { lado direito e } \\
\text { plantação agrícola } \\
\text { do lado esquerdo. }\end{array}$ \\
\hline CCA & $\begin{array}{l}\text { S: 26 50' } \\
24.48978^{\prime \prime} \\
\text { W: 51 59' } \\
12.61734^{\prime \prime}\end{array}$ & 1035 & CoPe & 7,08 & 1 & 0,8 & Se/Fo/Ar/La & $\begin{array}{l}\text { Vegetação ripária } \\
\text { nativa com } \\
\text { cobertura total em } \\
\text { toda margem, }\end{array}$ \\
\hline
\end{tabular}




\begin{tabular}{|c|c|c|c|c|c|c|c|c|c|}
\hline & & & & & & & & & $\begin{array}{l}\text { presença de muito } \\
\text { Xaxim. }\end{array}$ \\
\hline CAM & $\begin{array}{lc}\text { S: } \quad 26 & 4 \\
51.78247^{\prime \prime} & \\
\text { W: } \quad 51 & 5 \\
32.15106^{\prime \prime} & \end{array}$ & $\begin{array}{l}44^{\prime} \\
58^{\prime}\end{array}$ & 962 & $\mathrm{CoPe}$ & 10,58 & 1 & 0,16 & $\mathrm{Se} / \mathrm{Fo} / \mathrm{Ar} / \mathrm{La}$ & $\begin{array}{l}\text { Vegetação ripária } \\
\text { nativa com } \\
\text { cobertura total em } \\
\text { toda margem. }\end{array}$ \\
\hline CAD & $\begin{array}{lcl}\text { S: } \quad 26 & 4 \\
47.32767^{\prime \prime} & \\
\text { W: } \quad 51 & 4 \\
01.92391^{\prime \prime} & \end{array}$ & $\begin{array}{l}48^{\prime} \\
49^{\prime}\end{array}$ & 1090 & $\mathrm{CoPe}$ & $\mathrm{n} / \mathrm{m}$ & 1,5 & 0,90 & $\mathrm{Ar} / \mathrm{Fo} / \mathrm{La}$ & $\begin{array}{l}\text { Vegetação ripária } \\
\text { nativa com } \\
\text { cobertura total em } \\
\text { toda margem. }\end{array}$ \\
\hline CCF & $\begin{array}{lcr}\text { S: } \quad 26 & 4 \\
07.14379^{\prime \prime} & \\
\text { W: } \quad 51 & 5 \\
57.43969^{\prime \prime} & \end{array}$ & $\begin{array}{l}49^{\prime} \\
58^{\prime}\end{array}$ & 890 & Coln & 15,86 & 3 & 1,7 & $\mathrm{Se} / \mathrm{Fo} / \mathrm{La} / \mathrm{Ar}$ & $\begin{array}{l}\text { Vegetação ripária } \\
\text { nativa com } \\
\text { cobertura total em } \\
\text { toda margem. }\end{array}$ \\
\hline $\mathrm{RCZ}$ & $\begin{array}{lcl}\text { S: } \quad 26 & 4 \\
54.97010^{\prime \prime} & \\
\text { W: } \quad 51 & 5 \\
10.00662 " & \end{array}$ & $\begin{array}{l}46^{\prime} \\
59^{\prime}\end{array}$ & 798 & CoGa & 14,83 & 5 & 1,1 & $\mathrm{Se} / \mathrm{Ar}$ & $\begin{array}{l}\text { Vegetação ripária } \\
\text { nativa com } \\
\text { cobertura total em } \\
\text { toda margem. }\end{array}$ \\
\hline RCC & $\begin{array}{lcl}\text { S: } \quad 26 & 4 \\
33.76545^{\prime \prime} & \\
\text { W: } \quad 51 & 5 \\
24.04855^{\prime \prime} & \end{array}$ & $\begin{array}{l}41^{\prime} \\
56^{\prime}\end{array}$ & 936 & CoGa & 25,45 & 40 & 1,35 & $\mathrm{Se}$ & $\begin{array}{l}\text { Vegetação ripária } \\
\text { nativa com } \\
\text { cobertura total em } \\
\text { toda margem. }\end{array}$ \\
\hline RMT & $\begin{array}{lc}\text { S: } \quad 26 & 4 \\
56.39337^{\prime \prime} & \\
\text { W: } \quad 51 & 5 \\
55.40032^{\prime \prime} & \end{array}$ & $\begin{array}{l}49^{\prime} \\
52^{\prime}\end{array}$ & 1108 & CoGa & 12,42 & 10 & 5,5 & $\mathrm{Se} / \mathrm{Fo} / \mathrm{Ar} / \mathrm{La} / \mathrm{Ma}$ & $\begin{array}{l}\text { Vegetação ripária } \\
\text { nativa com } \\
\text { cobertura total em } \\
\text { toda margem. }\end{array}$ \\
\hline
\end{tabular}

\section{Amostragem de imaturos de Odonata}

Coletamos três amostras randomizadas e em cada ambiente, da seguinte forma: 1) quantitativas com o amostrador Surber (área de 0,9 $\mathrm{m}^{2}$ e malha de $300 \mu \mathrm{m}$ ); 2) qualitativas com a rede de arrasto (esforço amostral três minutos em cada corpo d'água na margem do ambiente, no substrato de fundo, e nas vegetações aquática e subaquática); e 3) qualitativa através de busca ativa nos mesmos ambientes amostrados na rede de arrasto, mas com o auxílio de peneira, durante trinta minutos. Em cada ambiente foram retiradas amostras extras de sedimento, para mensurar a textura granulométrica e o teor de matéria orgânica.

Em laboratório, pré-triamos as amostras em um sistema de peneiras com diferentes três aberturas de malhas (2,1 e 0,2 $\mathrm{mm}$ ) retirando os espécimes na primeira e na segunda peneiras a olho nu, enquanto o material retido na peneira de menor malha foi fixado em álcool 80\% para posterior triagem sob microscópio estereoscópico.

Identificamos as larvas de Odonata acordo com chaves de identificação especializadas (e.g. COSTA et al., 2004; FERNANDEZ et al., 2001). Consideramos para a identificação apenas os indivíduos com tecas alares mais desenvolvidas (últimos instares), pois as larvas muito jovens não apresentam características taxonômicas totalmente desenvolvidas. O material coletado está depositado no Laboratório de Ecologia e Química da Universidade Comunitária da Região de Chapecó, UNOCHAPECÓ.

\section{Análises físicas e químicas}

Simultaneamente às coletas de imaturos, medimos as variáveis físicas e químicas da água: $\mathrm{pH}$ (pHmetro digital 200A), oxigênio dissolvido (Oxímetro MO 890), temperatura (medidor de temperatura 
digital), profundidade, velocidade da correnteza e transparência (disco de Secchi). Para determinar a composição granulométrica do sedimento utilizamos a escala de Wentworth (WENTWORTH, 1922), que consiste na secagem de $100 \mathrm{~g}$ do sedimento em estufa, a aproximadamente $105^{\circ} \mathrm{C}$ durante $24 \mathrm{~h}$. $\mathrm{O}$ sedimento seco foi transferido para uma série de peneiras sobrepostas de diferentes aberturas de malha, onde cada malha corresponde ao tipo de sedimento (seixos, areia muito grossa, areia grossa, areia média, areia fina, areia muito fina e lama). $\mathrm{O}$ teor de matéria orgânica $(\mathrm{MO})$ foi realizado pela calcificação de uma subamostra do sedimento em mufla à temperatura de $550^{\circ} \mathrm{C}$ por quatro horas. $\mathrm{O}$ sedimento pesado anterior à queima foi novamente pesado determinando, portanto, a quantidade de $\mathrm{MO}$ no ambiente amostrado.

Obtivemos os dados referente a pluviosidade durante o período de coleta através da Empresa de Pesquisa Agropecuária e Extensão Rural de Santa Catarina (Epagri) de Chapecó. Consideramos os níveis registrados cinco dias antes e nos dias das coletas, devido à possível influência na composição da comunidade aquática. Constatamos o maior índice de pluviosidade no primeiro inverno (julho 2011) e na primavera (dezembro 2011), sendo esses, considerados como período chuvoso. Para as demais coletas consideramos como período de estiagem.

\section{Análise de dados}

Analisamos a diferenciação entre os ambientes e as estações amostradas quanto às variáveis ambientais da água e a pluviometria, utilizando a Análise de Componentes Principais (ACP) (MANLY, 1985), e para ordenar as variáveis de acordo com os ambientes e coleta (os dados foram transformados em Log $(x+1)$, exceto para $\mathrm{pH}$, para linearizar as relações e reduzir a dimensionalidade). Utilizamos para tais análises o programa Statistica $8.0^{\circledR}$.

Com a Análise de Correspondência Destendenciada ( $A C D$ ) avaliamos a estrutura da fauna de imaturos de Odonata, usando os gêneros mais abundantes, as variáveis ambientais da água e a pluviometria (dados também transformados em log10 $(x+1))$. Para confirmar a ordenação aplicamos o teste de Similaridade de Kruskal-Wallis (ANOVA) considerando o valor de $\mathrm{p}<0,05$ como significativo. Realizamos a ACD no PC-ORD 4.01 (MCCUNE et al., 1999). Analisamos diversidade e composição de imaturos de Odonata usando a abundância (N), a riqueza de gêneros $(S)$ e os índices de diversidade de Shannon-Wiener $\left(H^{\prime}, J\right)$ no programa PC-ORD, versão 4.01 (McCUNE et al., 1999).

Para verificar a significância das possíveis diferenças na riqueza $(\mathrm{S})$, diversidade $\left(\mathrm{H}^{\prime}\right)$, similaridade $(\mathrm{J})$ e abundância $(\mathrm{N})$ dos imaturos de Odonata entre os tamanhos dos ambientes amostrados, usamos análise não paramétrica de Kruskal-Wallis (Anova). Para os casos de diferenças significativas, aplicamos testes $a$ posteriori de comparação múltipla. Para essas análises foi utilizado o programa Statistica $8.0^{\circledR}$.

Através do índice de diversidade beta ( $\beta 2$ ) quantificamos alterações na composição de espécies entre os ambientes. $O$ índice é dado pela equação $\beta 2=[(R / \alpha \max )-1] /[N-1]$, onde $\alpha$ max é o valor máximo da riqueza de espécies no conjunto de $n$ amostras e R é o número total de táxonsem $n$ amostras (HARRISON et al., 1992). Utilizamos uma análise exploratória (análise de Cluster), no programa Past (HAMMER et al., 2001), para avaliar os principais padrões de similaridade (dados previamente transformados em Log $(x+1)$. Para testar 
riqueza, abundância, diversidade e equitabilidade em relação às variáveis químicas e físicas da água, e pluviometria de todas as coletas fizemos testes de Correlação de Spearman, com o auxílio do programa Statistica 8.0. A descrição dos dados baseou-se nas correlações significativas $(p<0,05)$.

\section{RESULTADOS}

Observamos a textura granulométrica do sedimento nos pequenos rios e córrego intermediário predominada por seixos. Para o rio Chapecozinho e rio Chapecó registramos altas porcentagem de seixos (99,4\% para os dois ambientes), seguido do córrego Casa de Força (seixos $95,4 \%)$ e rio do Mato $(79,6 \%)$. Nos pequenos córregos, a maior heterogeneidade da textura granulométrica ocorreu no córrego Caratuva com predomínio de areia.

Nos córregos grandes (rio Chapecozinho e rio Chapecó) registramos porcentagens de matéria orgânica menor que $10 \%$, portanto, prevaleceu o sedimento de tipo mineral. Nos demais ambientes, o sedimento fora predominantemente orgânico, sendo que os maiores valores foram observados para o córrego Casa de Força $(28,3 \%)$ e córrego Caratuva $(26,4 \%)$. Não visualizamos diferença significativa entre as concentrações de oxigênio dissolvido $\left(\mathrm{mg}^{-\mathrm{L}^{-1}}\right), \mathrm{pH}$ e temperatura da água em relação aos diferentes ambientes amostrados, porém, nos maiores corpos d'água, como os rios Chapecó, Chapecozinho e do Mato registramos as temperaturas mais elevadas. Para o oxigênio dissolvido destacamos o córrego Casa de Força, $8,3( \pm 0,6)$. Por fim, $\mathrm{pH}$ tendeu à neutralidade, variando de 6,7 a 7,2.

A maior variação temporal dentre as variáveis ambientais analisadas foi para temperatura da água, com desvio padrão de $1,4-4,5^{\circ} \mathrm{C}$, no córrego Casa da Árvore e rio Chapecó, respectivamente, sendo córregos grandes com maior variação. Das variáveis hidrológicas, a correnteza apresentou variação temporal, principalmente o rio Chapecó e córrego Ameixeira. Observamos maior velocidade da correnteza nos córregos grandes (ambientes de maior porte), destacando rio Chapecó $\left(25,5 \mathrm{~m} \cdot \mathrm{s}^{-1}\right)$ e córrego Casa de Força $(15,9 \mathrm{~m} / \mathrm{s}$ $\left.{ }^{1}\right)$.

Coletou-se 520 indivíduos de larvas de Odonata pertencentes às famílias Calopterygidae, Coenagrionidae, Dicteriadidae, Megapodagrionidae, Aeshnidae, Gomphidae e Libellulidae, distribuídas em 41 gêneros. As famílias com maior riqueza de gêneros pertencem à subordem Anisoptera: Libellulidae (12 gêneros), Gomphidae (10 gêneros) e Aeshnidae (oito gêneros). O gênero mais abundante foi Argia (Coenagrionidae, $\mathrm{N}=124$ ), seguido de Gomphoides (Gomphidae, $\mathrm{N}=58$ ), Hetaerina/Mneserate (Calopterygidae, $\mathrm{N}=57$ ), Dythemis (Libellulidae, $\mathrm{N}=46$ ) e Neuraeshna (Aeshnidae, $\mathrm{N}=23$ ). Para os demais gêneros registramos $S<17$ (Tabela 2).

Tabela 2: Distribuição de imaturos de Odonata, diversidade $\left(\mathrm{H}^{\prime}\right)$, Equitabilidade (J), Abundância absoluta (N) e relativa (\%), riqueza (s) no Parque Nacional das Araucárias, Santa Catarina, durante o período 2011 a 2012. CCR: córrego Caratuva; CCA: córrego Casa da Árvore; CAM: córrego Ameixeira; CAD: córrego Adami; CCF: córrego Casa de Força RCZ: rio Chapecozinho; RCC: rio Chapecó; RMT: rio do Mato. N: abundância. N \%: abundância relativa.

\begin{tabular}{|l|l|l|l|l|l|l|l|l|l|l|}
\hline & \multicolumn{2}{l}{ CoPe } & \multicolumn{2}{l|}{ Coln } & \multicolumn{2}{l|}{ CoGa } & N & N\% \\
\hline & CCR & CCA & CAM & CAD & CCF & RCZ & RCC & RMT & & \\
\hline ZYGOPTERA & & & & & & & & & & \\
\hline Calopterygidae & & & & & & & & & & \\
\hline
\end{tabular}




\begin{tabular}{|c|c|c|c|c|c|c|c|c|c|c|}
\hline Hetaerina/Mnesarete Selys 1853 & 17 & 1 & 8 & 17 & 6 & 1 & 1 & 6 & 57 & 10,9 \\
\hline \multicolumn{11}{|l|}{ Perilestidae } \\
\hline Perilestes Hagen 1862 & & & & & & & 2 & & 2 & 0,3 \\
\hline Coenagrionidae & & & & & 3 & & 1 & & 4 & 0,7 \\
\hline Gênero NI & & & & 1 & & & & & 1 & 0,1 \\
\hline Argia Rambur, 1842 & & 4 & & & 17 & 55 & 50 & & 126 & 24,2 \\
\hline Acanthagrion Selys, 1876 & & & & & & & 1 & & 1 & 0,2 \\
\hline \multicolumn{11}{|l|}{ Dicteriadidae } \\
\hline Dicterias Foerster, 1906 & & & & 2 & & & & & 2 & 0,3 \\
\hline \multicolumn{11}{|l|}{ Megapodagrionidae } \\
\hline Gênero NI & & & & 1 & & & & & 1 & 0,2 \\
\hline Gênero NI 2 & & & & 1 & & 1 & & & 2 & 0,4 \\
\hline Oxystigma Selys, 1862 & 3 & 2 & 6 & 3 & 2 & & & & 16 & 3,1 \\
\hline Heteragrion Williamson, 1919 & & & 2 & & 7 & 1 & & & 10 & 2 \\
\hline \multicolumn{11}{|l|}{ ANISOPTERA } \\
\hline Aeshnidae & 1 & & 1 & 2 & & & & 1 & 5 & 0,9 \\
\hline Aeshna Fabricius 1775 & & 5 & 9 & 1 & 2 & & & & 17 & 3,3 \\
\hline Castoraeshna Calvert 1952 & & 3 & & & & & & & 3 & 0,5 \\
\hline Limnetron Förster 1907 & & 2 & 3 & 2 & & & & & 7 & 1,4 \\
\hline Gênero NI & & & 1 & & 2 & & & & 3 & 0,6 \\
\hline Neoneura Selys, 1860 & & & & & & & & 3 & 3 & 0,6 \\
\hline Neuraeshna Hagen, 1867 & 2 & 12 & 4 & 3 & 2 & & & & 23 & 4,4 \\
\hline Anax Leach, 1815 & & & & 2 & & & & & 2 & 0,4 \\
\hline Gynacantha Rambur, 1842 & & 1 & & & & & & & 1 & 0,2 \\
\hline Gomphoidae & & 1 & 1 & 3 & & 1 & & 2 & 8 & 1,6 \\
\hline Progomphus Selys, 1854 & 2 & & 3 & 1 & & & 3 & & 9 & 1,7 \\
\hline Phyllogomphoides Hagen 1854 & 1 & 6 & 3 & & 1 & 2 & & 1 & 14 & 2,7 \\
\hline Cacoides Cowley, 1934 & & & & & & 1 & & & 1 & 0,2 \\
\hline Gomphoides Selys, 1854 & 2 & 7 & 29 & 16 & & 4 & & & 58 & 11,1 \\
\hline Aphylla Selys, 1854 & 1 & & & & 1 & & & & 2 & 0,4 \\
\hline Neogomphus Selys, 1858 & 1 & & & & & & & & 1 & 0,2 \\
\hline Cyanallagma Kennedy1920 & 2 & & & & & & & & 2 & 0,4 \\
\hline Desmogomphus Williamson, 1920 & & 2 & 1 & & & 2 & 4 & & 9 & 1,7 \\
\hline Enallagma Charpentier 1840 & & & & & & 1 & & & 1 & 0,2 \\
\hline Melanococus Williams 1985 & & & & & & & & 1 & 1 & 0,2 \\
\hline Libellulidae & 1 & 2 & 1 & & 4 & 1 & & & 9 & 1,7 \\
\hline Libellula Linnaeus, 1758 & & & & & 2 & 1 & & & 3 & 0,6 \\
\hline Erythrodiplax Brauer, 1868 & & & 1 & 4 & & & & & 5 & 1,00 \\
\hline Tauriphila Kirby 1889 & 2 & 3 & & & 2 & 3 & 1 & & 11 & 2,12 \\
\hline Brechmorhoga Kirby, 1894 & 1 & & & & & 1 & & & 2 & 0,4 \\
\hline Orthemis Hagen, 1861 & & & 1 & & & & & & 1 & 0,2 \\
\hline Perithemis Hagen 1861 & 5 & 10 & 2 & & 2 & & 9 & 1 & 29 & 5,6 \\
\hline Miathyria Kirby 1889 & & & & & & 2 & & & 2 & 0,4 \\
\hline Micrathyria Kirby, 1889 & & & & & 1 & & & & 1 & 0,2 \\
\hline Dasythemis Karsch 1889 & & & 2 & & & & & & 2 & 0,4 \\
\hline Tramea Hagen 1861 & & & & 1 & & & & & 1 & 0,2 \\
\hline Dythemis Hagen 1861 & 4 & 3 & & 1 & 33 & 1 & & 4 & 46 & 8,9 \\
\hline Oxyagrion Selys 1876 & 1 & & & & & & & 15 & 16 & 3,1 \\
\hline Abundância total (N) & 46 & 64 & 78 & 61 & 87 & 78 & 72 & 34 & 520 & \\
\hline Riqueza total (S) & 14 & 14 & 15 & 15 & 14 & 14 & 8 & 7 & 41 & \\
\hline Diversidade ( $\left.\mathrm{H}^{\prime}\right)$ & 0,81 & 0,91 & 0,79 & 0,77 & 0,72 & 0,48 & 0,52 & 0,77 & & \\
\hline Equitabilidade (J) & 2,15 & 2,39 & 2,13 & 2,08 & 1,91 & 1,26 & 1,09 & 1,49 & & \\
\hline
\end{tabular}

Os ambientes da categoria CoPe apresentaram maior riqueza de gêneros, por exemplo, 16 gêneros no córrego Ameixeira registrados, 15 para os córregos Adami e Casa da Árvore, e 14 para o córrego Caratuva. Para os ambientes CoGa registramos as menores riquezas (10 e 7 táxons para rio Chapecó e do Mato, respectivamente) (Tabela 2). Os ambientes com maior diversidade Shannon ( $\left.\mathrm{H}^{\prime}\right)$ foram os de CoPe, sendo o córrego Casa da Árvore com maior diversidade $\left(\mathrm{H}^{\prime}=2,42\right)$ enquanto que os demais apresentaram $\mathrm{H}^{\prime}$ variando entre 2,17 e 2,08, representando, ainda assim, valores elevados se comparados com os ambientes de Coln e CoGa. No córrego Casa de Força (Coln) registramos diversidade intermediária $\left(H^{\prime}=1,87\right)$ entre os CoPe e 
CoGa (Tabela 2). $O$ índice de equitabilidade foi elevado para a maioria dos ambientes e variou entre 0,73 e 0,81 (Tabela 2).

A relação entre riqueza $(\mathrm{S})$, diversidade $\left(\mathrm{H}^{\prime}\right)$ e equitabilidade $(\mathrm{J})$ e o tamanho dos corpos d'água, registramos diferenças significativas $(p<0,05)$, mas nenhum padrão para a abundância $(N)(p>0,05)$ (Figura 2). Os valores para esses atributos foram maiores em $\mathrm{CoPe}$, intermediários em Coln e menores em CoGa (Figura 3). Desta forma, o ambiente categorizado como Coln, realmente apresenta características intermediárias se comparado com os outros dois agrupamentos, não diferenciando estatisticamente para S, $\mathrm{H}^{\prime}$ e J (Figura 3 b, c e d). Por outro lado, CoPe e CoGa diferiram significativamente para esses atributos, mostrando um padrão de maiores índices nos córregos pequenos (Figura 2 b, c e d).
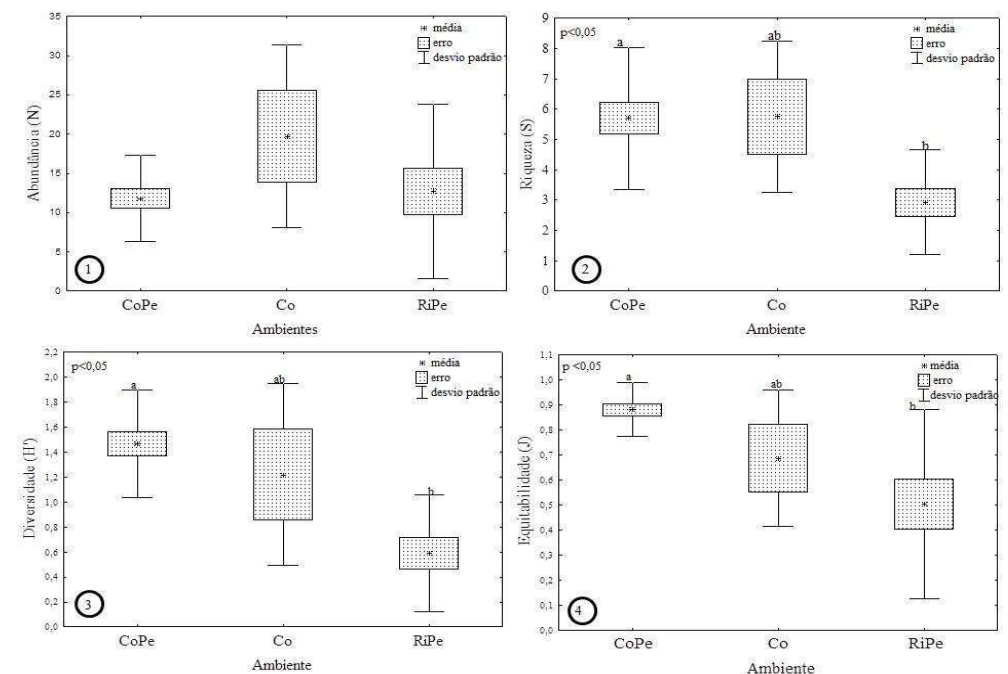

Figura 2: Valores de média, erro e desvio padrão de 1: abundância (N), 2: riqueza (S), 3:diversidade ( $\left.H^{\prime}\right)$ e 4: equitabilidade $(\mathrm{J})$ de imaturos de Odonata nos diferentes tamanhos de ambientes lóticos no Parque Nacional das

Araucárias, Santa Catarina. CoPe: córrego pequeno; Coln: córrego Intermediário; CoGa: córrego grande.

Na ACP relativa às variáveis físicas e químicas da água, e hidrológicas, os dois primeiros eixos explicaram $69 \%$ da variação total. As principais variáveis responsáveis pela separação dos ambientes no eixo 1 foram composição granulométrica, matéria orgânica e largura dos corpos d'água, enquanto a temperatura da água foi a variável que mais contribuiu para a formação do eixo 2 .

A ordenação da ACP do eixo 1 sobre o eixo 2 apresentou correlação positiva (aproximadamente 70\%) para os córregos grandes, a partir do substrato seixo e da largura dos corpos d'água no eixo 1. Para os córregos pequenos, a composição granulométrica e a matéria orgânica foram negativamente correlacionadas, enquanto o córrego intermediário não apresentara relação significativa (Figura 2). No eixo 2 a temperatura correlacionou-se de forma negativa com os corpos pequenos. Para testar a ACP: teste de Kruskall (ANOVA) usando o eixo 1 , onde $p<0,05(p=0,001)$.

Através da análise de correspondência destendenciada ( $A C D)$ para abundância dos táxons de Odonata, observamos que os ambientes foram agrupados conforme sua classificação de tamanho (CoPe, Coln e CoGa). CoPe e Coln foram agrupados em função dos gêneros mais abundantes (Figura 4). 


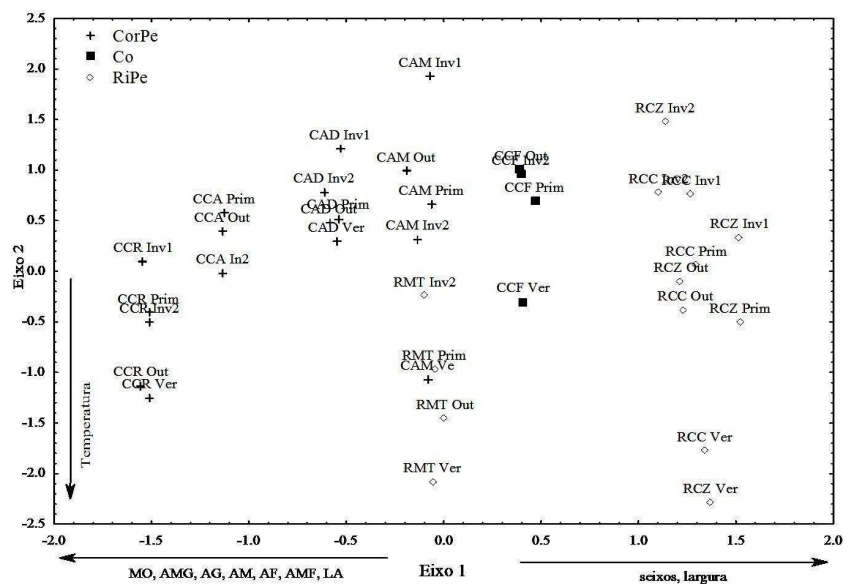

Figura 3: Ordenação dos escores de DCA baseados nas variáveis físicas e químicas, mostrando a distribuição nos dois eixos, no Parque Nacional das Araucárias, Santa Catarina, período de 2011 a 2012. ${ }^{1}$

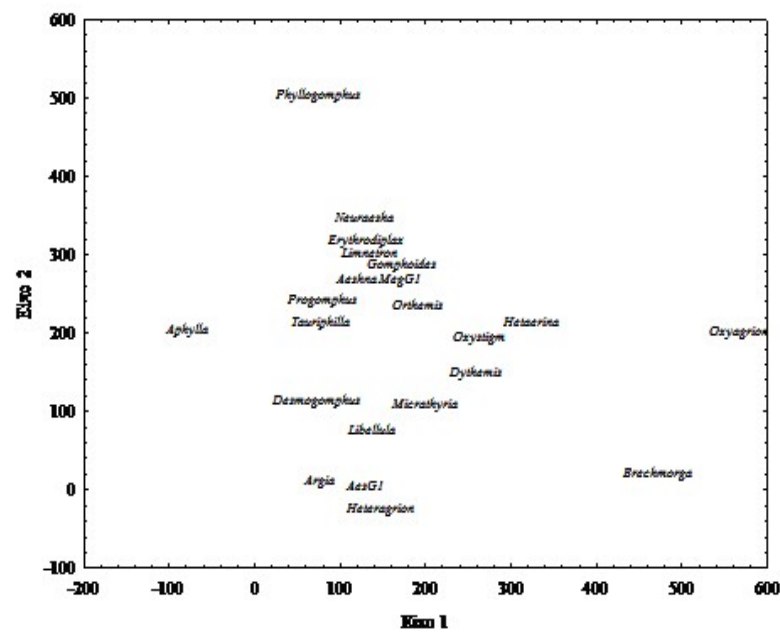

Figura 4: Ordenação de escores dos ambientes amostrados e imaturos de Odonata do Parque Nacional das Araucárias, Santa Catarina, período 2011 e 2012. ${ }^{2}$

O índice de diversidade Beta $\left(\beta_{2}\right)$ alcançou valor máximo de 0,67 de variação de diversidade entre os ambientes, sendo o CoGa rio Chapecozinho o mais dissimilar em relação aos ambientes CoPe (córrego Caratuva, córrego Casa da Árvore, córrego Ameixeira e córrego Adami) e ao Coln (córrego Casa de Força) variando de 0,67 a 0,50. O córrego Adami apresentou maior $\aleph_{2}$ em relação ao rio Chapecó $(0,62)$ e córrego Casa de Força $(0,60)$, demonstrando as maiores dissimilaridade espaciais do estudo (Tabela 3). Outro registro de alta dissimilaridade foi para o córrego Caratuva e córrego Adami $(0,53)$. Em geral, os córregos grandes apresentaram similaridade na composição de larvas de Odonata (Tabela 3).

Tabela 3: Valores dos índices de diversidade $ß_{2}$ dos gêneros de Imaturos de Odonata no Parque Nacional das Araucárias, Santa Catarina, período entre 2011 e 2012.CCR: córrego Caratuva; CCA: córrego Casa da Árvore; CAM: córrego Ameixeira; CAD: córrego Adami; CCF: córrego Casa de Força RCZ: rio Chapecozinho; RCC: rio Chapecó; RMT: rio do Mato. Em negrito e sublinhados os valores mais altos de diversidade Beta.

\begin{tabular}{|l|l|l|l|l|l|l|l|l|}
\hline & CCR & CCA & CAM & CAD & CCF & RCZ & RCC & RMT \\
\hline CCR & $\mathbf{0}$ & $*$ & $*$ & $*$ & $*$ & $*$ & $*$ & $*$ \\
\hline CCA & $\mathbf{0 , 4 2 8}$ & $\mathbf{0}$ & $*$ & $*$ & $*$ & $*$ & $*$ & $*$ \\
\hline CAM & $\mathbf{0 , 4 6 6}$ & $\mathbf{0 , 3 3 3}$ & $\mathbf{0}$ & $*$ & $*$ & $*$ & $*$ & $*$ \\
\hline CAD & $\mathbf{0 , 5 3 3}$ & $\mathbf{0 , 4 6 6}$ & $\mathbf{0 , 4 6 6}$ & $\mathbf{0}$ & $*$ & $*$ & $*$ & $*$ \\
\hline RCF & $\mathbf{0 , 4 2 8}$ & $\mathbf{0 , 3 5 7}$ & $\mathbf{0 , 4}$ & $\underline{\mathbf{0 , 6 0 0}}$ & $\mathbf{0}$ & $*$ & $*$ & \\
\hline RCC & $\underline{\mathbf{0 , 5 7 1}}$ & $\mathbf{0 , 5 0 0}$ & $\underline{\mathbf{0 , 6 0 0}}$ & $\underline{\mathbf{0 , 6 6 6}}$ & $\mathbf{0 , 5 0 0}$ & $\mathbf{0}$ & $*$ & $*$ \\
\hline RMT & $\mathbf{0 , 2 8 5}$ & $\mathbf{0 , 2 1 4}$ & $\mathbf{0 , 2 6 6}$ & $\mathbf{0 , 4 0 0}$ & $\mathbf{0 , 2 8 5}$ & $\mathbf{0 , 2 8 5}$ & $\mathbf{0}$ & $*$ \\
\hline
\end{tabular}

Para o agrupamento dos ambientes quanto ao índice de diversidade $\aleph_{2}$ usamos a análise de agrupamento (Cluster), com os valores de $\aleph_{2}$, os quais foram unidos a maior similaridade, formando claramente dois grupos, correspondentes aos mais dissimilares, rio Chapecozinho e córrego Adami (1ํ grupo) e rio do Mato e rio Chapecó (2ํㅜ) (Figura 5).

\footnotetext{
${ }^{1}$ CCR: córrego Caratuva; CCA: córrego Casa da Árvore; CAM: córrego Ameixeira; CAD: córrego Adami; CCF: córrego Casa de Força RCZ: rio Chapecozinho; RCC: rio Chapecó; RMT: rio do Mato; Inv 1: inverno 1; Pri: primavera; Ver: verão; Out: outono; Inv 2: inverno 2; MO: matéria orgânica; AMG: areia muito grossa; AG: areia grossa; AM: areia média; AF: areia fina; AMF: areia muito fina; LA: lama; CoPe: córrego pequeno; Coln: córrego intermediário; CoGa: córrego grande.

${ }^{2}$ CoPe: córrego pequeno; Coln: córrego intermediário; CoGa: córrego grande; CCR: córrego Caratuva; CCA: córrego Casa da Árvore; CAM: córrego Ameixeira; CAD: córrego Adami; CCF: córrego Casa de Força RCZ: rio Chapecozinho; RCC: rio Chapecó; RMT: rio do Mato.
} 


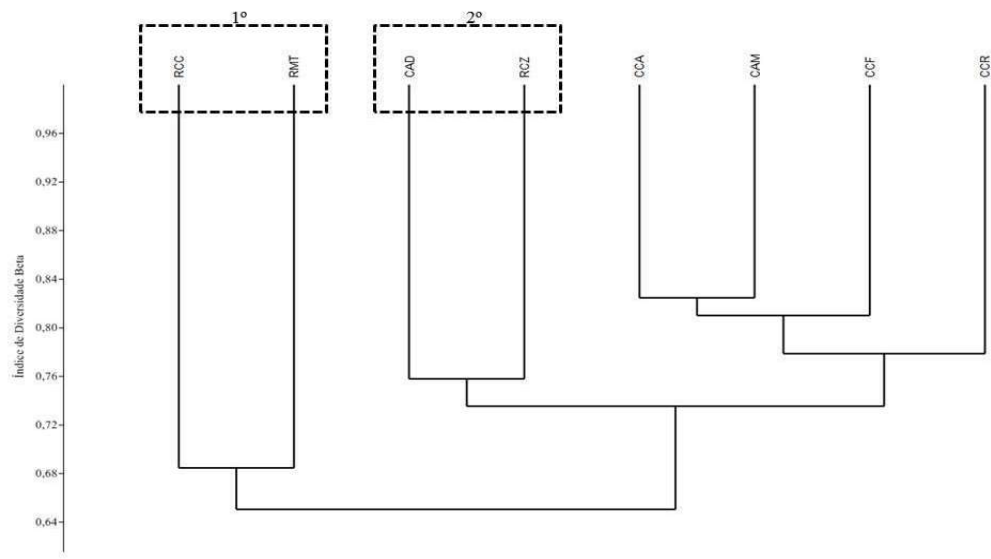

Figura 5: Análise de agrupamento dos ambientes amostrados pela diversidade beta $ß_{2}$ no Parque Nacional das Araucárias, Santa Catarina, entre 2011 e 2012.CCR: córrego Caratuva; CCA: córrego Casa da Árvore; CAM: córrego Ameixeira; CAD: córrego Adami; CCF: córrego Casa de Força RCZ: rio Chapecozinho; RCC: rio Chapecó; RMT: rio do Mato.

A riqueza $(S)$ correlacionou-se com correnteza e temperatura $(r=-0,759$ e $r=-0,939)$, enquanto o $\mathrm{pH}$ teve efeito negativo sobre a abundância de Hetaerina/Mnesarete. Os gêneros Oxystigma, Aeshna, Neuraeshna e Gomphoides foram mais abundantes nos ambientes de menor temperatura (Tabela 4). Por outro lado, a correnteza influenciou negativamente a abundância de Neuraeshna e Gomphoides. Gomphoides foi correlacionado com largura dos ambientes, com sua maior abundância nos ambientes de menor largura. A ocorrência e a abundância de Tauriphila esteve relacionada com os maiores valores de OD. Perithemis esteve relacionada à sedimentos mais grossos, pois mostrou correlação negativa com areia muito fina (Tabela 4). As demais variáveis que não apresentaram valores significativos podem influenciar a ocorrência de gêneros, mas não são fatores limitantes para a diversidade de Odonata.

Tabela 4: Correlação de Spearman entre a riqueza de gêneros e os gêneros mais abundantes de imaturos de Odonata com variáveis físicas, químicas e hidrológicas, no Parque Nacional das Araucárias, Santa Catarina, durante o período entre 2011 e 2012. OD = Oxigênio dissolvido; AF = Areia Fina.

\begin{tabular}{|c|c|c|c|c|c|c|c|c|c|c|c|c|}
\hline Táxons & Corrent & & Tempe & tura & Largura & & $\mathrm{pH}$ & & OD & & AF & \\
\hline & $r$ & $p$ & $r$ & $p$ & $r$ & $p$ & $r$ & $p$ & $r$ & $p$ & $r$ & $p$ \\
\hline Riqueza (S) & $-0,759$ & 0,020 & $-0,939$ & 0,001 & & & & & & & & \\
\hline $\begin{array}{l}\text { Hetaerina/ } \\
\text { Mnesarete }\end{array}$ & & & & & & & $-0,729$ & 0,040 & & & & \\
\hline Oxystigma & & & $-0,901$ & 0,002 & & & & & & & & \\
\hline Aeshna & & & $-0,740$ & 0,036 & & & & & & & & \\
\hline Neuraeshna & $-0,773$ & 0,024 & $-0,889$ & 0,003 & & & & & & & & \\
\hline Gomphoides & $-0,805$ & 0,016 & $-0,871$ & 0,005 & $-0,781$ & 0,022 & & & & & & \\
\hline Tauriphila & & & & & & & & & 0,801 & 0,017 & & \\
\hline Perithemis & & & & & & & & & & & $-0,771$ & 0,020 \\
\hline
\end{tabular}

\section{DISCUSSÃO}

Os ambientes pesquisados, de uma maneira geral, têm características morfológicas diferentes, porém ambos representaram elevada heterogeneidade, e ainda que tenha predomínio de seixos, encontramos um substrato diversificado, rico em matéria orgânica. Já em relação às variáveis químicas, verificamos homogeneidade nos índices.

As propriedades que compuseram o sedimento (textura granulométrica) apresentaram grande relevância para este estudo. Nos córregos grandes, houve um predomínio de seixos, característico de 
ambientes maiores, por terem maiores fluxos de água e entrada de radiação solar (BATISTA, 2006). Para os córregos pequenos, os seixos também se destacaram (como o córrego Caratuva), porém mais heterogêneo. Esse ambiente, em especial, é o único que possui uma margem com predomínio de monocultura e a outra de mata ciliar, acarretando o recebimento de diferentes materiais alóctones.

O percentual de matéria orgânica no sedimento, segundo Ungemach (1960) citado por Esteves (1998), pode ser classificado como sedimento mineral (menos de $10 \%$ do peso seco) e orgânico (mais de 10\%). Maiores índices de matéria orgânica foram registrados para os córregos pequenos, e os menores nos córregos grandes, divergindo da teoria da continuidade fluvial (VANOTTE et al., 1980), que cita que conforme o rio aumenta de tamanho ocorre um acréscimo de matéria orgânica. Os córregos pequenos são ambientes de baixa correnteza, logo, indicam maior quantidade de matéria orgânica, por apresentarem mais regiões de várzea (TUNDISI, 2008).

$\mathrm{Na}$ ordenação das variáveis físicas e químicas relacionadas aos ambientes nas diferentes coletas, a largura do rio e a presença de seixos foram correlacionados com os córregos grandes, isso pode ter ocorrido pelo predomínio de seixos nesses ambientes e por serem os mais largos. Os demais componentes da textura granulométrica, areia muito grossa, areia grossa, areia média, areia fina, areia muito fina e lama, juntamente a matéria orgânica, representaram forte correlação com os córregos pequenos, provavelmente devido à alta heterogeneidade nos mesmos.

A temperatura da água diferiu entre córregos grandes e córregos pequenos. Nos córregos grandes registramos as maiores amplitudes, destacando o ciclo sazonal, com maiores temperaturas no verão e menores no inverno, mesmo registrado por Allan (1995), Suhling (1995) e Higuti (2007), que pode estar associado à cobertura vegetal marginal, deixando os corpos d'água em maior contato com meio (radiação solar, chuva, vento...).

Altos teores de oxigênio dissolvido na água também foram verificados, tanto em nos córregos pequenos quanto nos grandes, circunstâncias essas vantajosas, já que organismos aquáticos necessitam de elevadas quantidades (WHITTON, 1975; SANTOS et al., 2009). Geralmente, nos rios, ocorre maior oxigenação devido principalmente à maior turbulência, que favorece a difusão do oxigênio do ar para a água. Os valores de $\mathrm{pH}$ tenderam a neutralidade, no entanto, córrego Casa da Árvore e rio do Mato foram encontrados valores levemente ácidos. Em todos os ambientes amostrados foram apontados valores de $\mathrm{pH}$ inferiores a 8, sendo fator positivo para Odonata, já que tem preferência por pH neutro (SILVA et al., 2007).

Quanto à pluviosidade, nos períodos com estiagem tanto a riqueza quanto a abundância foram mais representativas. Maior frequência de táxons no período seco pode estar relacionada ao menor volume de águas neste período, e no período chuvoso, o aumento do volume de água e da velocidade da corrente provavelmente provocam uma remoção dos organismos (KIKUCHI et al., 1998; BISPO et al., 2001). Flecker et al. (1994) fazem referência à tendência, em ambientes lóticos tropicais, a diminuir da abundância de insetos aquáticos em estações chuvosas. Um efeito das precipitações sobre o aumento da diversidade já havia sido registrado em estudo mundial sobre a distribuição das libélulas (KALKMAN et al., 2008; FULAN et al., 2007). 
Os tamanhos dos ambientes também interferiram na composição da fauna. O córrego intermediário apresentou a maior abundância de imaturos, o que pode ser explicado pela diversidade de condições ali existentes, como presença de matéria orgânica, de mata ciliar e de maior velocidade da água. Vegetação, composição do substrato e correnteza foram as variáveis mais significativas para explicar a distribuição de Odonata observada (HYNES, 1970) pois modela o leito do rio, determinando uma heterogeneidade ambiental observável mesmo em trechos curtos, corroborando com Uieda et al. (1996).

Nos córregos pequenos averiguamos alta riqueza de Odonata, ao contrário dos córregos grandes. Os indivíduos de ambientes aquáticos de uma região podem variar significativamente em riqueza e composição e, como Odonata, muitas espécies, necessitam de ambientes com alta diversidade de hábitats e microhábitats (SANTOS et al., 2009), justificando a riqueza, diversidade e equitabilidade dos ambientes amostrados influenciadas significativamente pelo tamanho dos corpos d'água $(p<0,05)$.

Os ambientes mais diversos em relação à diversidade foram os córregos pequenos, que apresentam importante componente dos sistemas lóticos, como vegetação marginal (dossel fechado) impedindo que haja arraste excessivo de sedimento para o rio, além de interceptar e absorver a radiação solar, o que contribui para a estabilidade térmica dos pequenos cursos d'água (STEINBLUMS et al., 1984; FERREIRA-PERUQUETTI et al., 2002); correnteza moderada e remansos, favorecendo uma heterogeneidade espacial fornecida pela vegetação contribui para a abundância de invertebrados, atuando como suporte para guildas de possíveis presas, fornecendo refúgio contra predadores (WARD, 1989; MARCO Jr. et al., 1998). Corbet (1995), da mesma forma, encontrou maior número de famílias de Odonata em riachos com correnteza moderada da zona tropical. Baptista et al. (1998) e Assis et al. (2004) corroboraram com estudos em riachos do sudeste brasileiro em que Odonata apresentou maior riqueza e abundância em substratos de folhiço de fundo de riachos, porém com baixo fluxo de água. Hepp (2005) averiguou que na bacia do Rio Jacutinga a presença de Odonata foi restrita a região de cabeceira do rio, onde a presença de vegetação é mais abundante.

Ao contrário dos córregos supracitados, nos córregos grandes foram registradas menores riquezas e diversidade, provavelmente em relação ao predomínio de seixos, pois em áreas rochosas a comunidade bentônica é controlada (LENAT et al., 1981). A correnteza pode exercer um efeito direto sobre organismos quando em período de grande vazão, as pedras no fundo do rio são deslocadas, ocasionando a remoção de organismos que estão sobre e entre o substrato (WHITTON, 1975). Para o rio do Mato, foram registrados os menores índices de riqueza, abundância e diversidade, isso pode ter ocorrido pela correnteza e fluxo de água serem maiores. Esses resultados foram encontrados, possivelmente, pela temperatura nos córregos grandes mais elevada, além da maior amplitude, já que em locais que apresentam temperaturas mais elevadas tendem a mostrar menor densidade e riqueza de espécies (CORBET, 1999; FULAN et al., 2006). Outro fator que pode ter influenciado foi a velocidade da correnteza, uma vez que exerce força em que muito organismos estão sujeitos, além de limitar a disponibilidade de material suspenso na coluna d'água (CARVALHO, 1994; ALLAN, 1995).

O índice de diversidade de Shannon maior nos córregos pequenos, assim como no córrego intermediário (Casa de Força) reforça a condição de serem ambientes com características mais favoráveis 
para a fauna de Odonata. Altos valores de diversidade de Shannon ocorrem devido à disponibilidade de recursos alimentares e diversidade de habitats (TREVISAN et al., 2004). Dentre essas características ambientais, algumas influenciam mais diretamente a distribuição, abundância e riqueza de imaturos de Odonata, como a textura granulométrica e percentual de matéria orgânica (VOS et al., 2002; BROWN, 2007; SARRIQUET et al., 2007). O substrato de águas correntes difere de lugar para lugar, e é importante para muitas comunidades, pois servem de abrigo da corrente e de predadores (KIKUCHI et al., 1998).

A dissimilaridade referente ao Índice de diversidade $\beta_{2}$ entre o córrego Adami e o rio Chapecozinho, e entre o córrego Ameixeira e rio Chapecozinho, provavelmente ocorreu pelas diferentes características desses ambientes (largura, profundidade, substrato, matéria orgânica) contribuindo para mais variada composição taxonômica. Os córregos grandes representaram os valores mais baixos, ou seja, ambientes mais similares entre si. Para Windberg et al. (2007) baixa diversidade beta em escalas menores indica uma homogeneidade de habitats, servindo como um bom indicativo para o direcionamento de esforços na conservação da biodiversidade.

Variáveis físicas dos corpos d'água que podem afetar a ordem, são: tamanho, vegetação, profundidade, composição do substrato, correnteza, temperatura, entre outros (WRIGHT, 1943). Algumas poucas correlações foram significavas entre a fauna e as variáveis físicas, químicas e hidrológicas com os indivíduos coletados. A riqueza da fauna de Odonata foi negativamente correlacionada com a correnteza e temperatura da água, provavelmente está ligada a baixa riqueza em ambientes com corredeira e com amplitudes de temperaturas maiores.

Os táxons Oxystigma, Aeshna, Neuraeshna e Gomphoides foram significativamente correlacionados com a menor temperatura da água. Wheaton (1987) cita que a temperatura da água provavelmente tem maior influência sobre a vida e os sistemas aquáticos do que qualquer outra variável isoladamente. Os efeitos da temperatura da água sobre a densidade e o desenvolvimento das larvas de Odonata são conhecidos (LUTZ, 1974; CORBET, 1999; SUHLING et al., 2004). Locais que apresentam temperatura mais elevada tendem a mostrar menor densidade e riqueza de espécies (FULAN et al., 2006).

A correnteza da água mostrou correlação negativa com abundância de Neuraeshna e Gomphoides. Já Gomphoides foi correlacionado com largura dos riachos, sendo as maiores abundâncias registradas nos ambientes de menor largura. Gomphoides, por exemplo, tem preferência por ambientes lóticos com predomínio de areia e águas mais calmas (CARVALHO et al., 1998). A baixa velocidade da correnteza em remansos permite que detritos de maior porte, como pedaços de troncos, gravetos e folhas, até mesmo partículas menores, sejam mais facilmente carreadas se acumulem (YOKOYAMA, 2012). O gênero Gomphoides tem necessidade essencial do efeito da correnteza, ou porque precisam desse efeito para alimentação, ou por exigências respiratórias (HYNES, 1970). A velocidade da correnteza também pode agir sobre a natureza do substrato, e deste modo, atuar indiretamente sobre a composição das comunidades de macroinvertebrados (WITTON, 1975).

Os maiores valores de oxigênio dissolvido relacionados com Tauriphila também foram registrados por Cunha et al. (2013) na região amazônica. A dependência de Perithemis por sedimentos mais grossos 
consiste, provavelmente, de uma similaridade geral entre outros insetos aquáticos, que são influenciados pelos tipos de substratos disponíveis (MINSHALL, 1984; HANNAFORD et al., 1997; HILSENHOFF, 2001; SCHOWALTER, 2006).

A matéria orgânica fornece aos imaturos recursos de sobrevivência, tornando-se um fator muito relevante (ROBERTSON et al., 2001). Odonata são exclusivamente predadoras (WESTFALL et al., 1996; CORBET, 1999; MUGNAl et al., 2010), mas utilizam, também, como recurso alimentar, os imaturos que se alimentam de matéria orgânica. Logo, onde a comunidade é numerosa aumenta a disponibilidade de alimentos para a ordem. A disponibilidade de alimento também pode controlar a ocorrência e abundância das espécies, as quais são observadas somente onde seu alimento está disponível (HYNES, 1970).

\section{CONCLUSÕES}

O Parque Nacional das Araucárias apresenta importante diversidade biológica quanto à odonatofauna, pois foi registrado um número elevado de gêneros, resultado dificilmente alcançado em um pequeno espaço de tempo de coleta. Além disso, pode-se averiguar que a heterogeneidade de ambientes contribui para a distribuição e a composição da fauna de imaturos de Odonata, e que esses parâmetros sofrem influências sobre as diferenças geomorfológicas dos tamanhos dos ambientes devido a diferentes resultados nas variáveis físicas e químicas. Confirmou-se a importância de correlacionar os fatores químicos, físicos e hidrológicos com a fauna de Odonata para entender sua composição e distribuição. Dessas variáveis, as mais significantes foram correnteza, temperatura e composição granulométrica dos corpos d'água.

A distribuição dos imaturos de Odonata não correspondeu ao conceito do contínuo fluvial, pois houve grande variação de índices nos trechos de nascente até intermediários, não apresentando um padrão de distribuição elevada nos riachos ou rios intermediários. Nos córregos pequenos os índices de riqueza, de equitabilidade e de diversidade foram mais elevados, refutando a hipótese desse trabalho, a qual pressupunha que os corpos lóticos sustentam diversidade e distribuição de imaturos de Odonata similar nas diferentes dimensões de corpos d'água.

O índice de diversidade $\beta_{2}$ apresentou dissimilaridade entre os tamanhos de ambientes, enfatizando a influência das características desses, maior dissimilaridade foi registrada entre os córregos menores e o rio Chapecozinho, indicando que compartilham o menor número de gêneros semelhantes. A disponibilidade de recursos alimentares para os invertebrados consumidores pode ter aumentado a fauna de imaturos de Odonata nesses ambientes. Posto isso, consideramos relevante a proteção da mata ciliar, consequentemente das nascentes e córregos.

AGRADECIMENTOS: Ao ICMBIO pela logística e apoio financeiro, à CAPES e à UNOCHAPECÓ pela bolsa de estudos.

\section{REFERÊNCIAS}

ALLAN, J. D.. Stream ecology: Structure and function of running waters. London: Chapman \& Hall, 1995. 
ASSIS, J. C. F.; CARVALHO, A. L.; NESSIMIAN, J. L.. Composição e preferência por microhábitat de imaturos de Odonata (Insecta) em um trecho de baixada do Rio Ubatiba, Maricá-RJ, Brasil. Revista Brasileira de Entomologia, v.48, n.2, p.273-282, 2004.

BAPTISTA, D. F.; DORVILLÉ, L. F. M.; BUSS, D. F.; NESSIMIAB, J. L.; SOARES, L. H. J.. Distribuição de comunidades de insetos aquáticos no gradiente longitudinal de uma bacia fluvial do sudeste brasileiro. Ecologia de Insetos Aquáticos, Rio de Janeiro, v.5, n.1, p.191-207, 1998. DOI: http://10.4257/oeco.1998.0501.14

BATISTA, J. D.. Distribuição longitudinal de adultos de Odonata em riachos no cerrado: uma hipótese ecofisiológica. Dissertação (Mestrado em Entomologia) Universidade Federal de Viçosa, 2006.

BISPO, P. C.; OLIVEIRA, L. G.; CRISCI, V. L.; SILVA, M. M.. A pluviosidade como fator de alteração da entomofauna bentônica (Ephemeroptera, Plecoptera e Trichoptera) em córregos do planalto Central do Brasil. Acta Limnologica Brasiliensia, v.13, n.2, p.1-9, 2001.

BROWN, A. V.; BRUSSOCK, P. P.. Comparisons of benthic invertebrates between riffles and pools. Hydrobiologia, v.220, p.99-108, 1991.

CALLISTO, M.; GONÇALVES JR.; J. F., MORENO, P.. Invertebrados aquáticos como bioindicadores. In: Goulart, E.M.A.. Navegando o Rio das Velhas das Minas Gerais. Belo Horizonte, 2004.

CARVALHO, A. L.; SALGADO, L. G. V.. Descrição da larva de Aeshna pauloi Machado, 1994 (Odonata, Aeshnidae), com uma chave de identificação para as larvas conhecidas do gênero ocorrentes nos estados do Rio de Janeiro e São Paulo, Brasil. Boletim do Museu Nacional. Zoologia, Rio de Janeiro, v.485, p.1-8, 2002.

CARVALHO, A. L.; NESSIMIAN, J. L.. Odonata do Estado do Rio de Janeiro, Brasil: Hábitats e hábitos das larvas. In: NESSIMIAN, J. L.; CARVALHO, A. L.. Ecologia de Insetos Aquáticos. Series Oecologia Brasiliensis. v.5. Rio de Janeiro: PPGEUFRJ, 1998. p.3-28.

CORBET, P.. Habitats and habitats of world dragonflies and the need to conserve species and habitat. Kushiro: Jap. Soc. Preservation of Birds, 1995.

CORBET, P.. Dragonflies: Behavior and Ecology of Odonata. Ithaca: Cornell University Press, 1999.

COSTA, J. M.; SOUZA, L. O. I.; OLDRINI, B. B.. Chave para identificação das famílias e gêneros das larvas conhecidas de Odonata do Brasil: comentários e registros bibliográficos. Publicações Avulsas do Museu Nacional, Rio de Janeiro, v.99, p.1-44, 2004.

CUMMINS, K. W.. Trophic relations of aquatic insects. Annu. Rev. Entomol., v.18, p.183-206, 1973.

CUMMINS, K. W.; KLUG, M. J... Feeding ecology of stream invertebrates. Annu. Rev. Ecol., v.10, p.147-172, 1979.

CUNHA, R. C.; SANTOS, L. R.. Influência das características físicas e químicas da água na distribuição espacial de larvas de Odonata associadas à Eichhornia crassipes (Mart.) Solms no Rio Uruapiara, afluente do Rio Madeira/AM. Estudos de Biologia, v.36, p.36, 2014. DOI:

http://10.7213/estud.biol.36.086.AO04

DOMINGUEZ, E.; HUBBARD, M. D.; PESCADOR, M. L.; MOLINERI, C.. Ephemeroptera. In: FERNANDEZ, H. R.; DOMINGUEZ, E.. Guía para la Determinación de los Artrópodos Bentónicos Sudamericanos. Tucumán: Universitaria de Tucumán, 2001.

ESTEVES, F. A.. Fundamentos de Limnologia. 3 Ed. Rio de Janeiro: Interciência, 2011.

FERREIRA-PERUQUETTI, P.; MARCO JR, P.. Efeito da alteração ambiental sobre comunidades de Odonata em riachos de Mata Atlântica de Minas Gerais, Brasil. Revista Brasileira de Zoologia, v.19, n.2, p.317-327, 2002.

FLECKER, A. S.; FEIFAREK, B.. Disturbance and the temporal variability of invertebrate assemblages in two Andean streams. Freshwater Biology, v.31, n.2, p.131-142, 1994.

FULAN, J. A.; HENRY, R.. The Odonata assemblage on Eichhornia azurea stands in Camargo Lake, a lateral lake on the Paranapanema River (São Paulo), after an extreme inundation episode. Acta Limnologica Brasiliensia, v.18, p.423-431, 2006

FULAN, J. A.; HENRY, R.. Distribuição temporal de imaturos de Odonata (Insecta) associados a Eichhornia azurea (Kunth) na Lagoa do Camargo, Rio Paranapanema, São Paulo. Revista Brasileira de Entomologia, v.51, n.2, p.224-227, 2007.

HAMMER, O.; HARPER, D. A. T.; RYAN, P. D.. PAST: Paleontological Statistics Software Package for Education and Data Analysis. Palaeontologia Electronica, v.4, n.1, p.9, 2001.

HARRISON, S.; ROSS, S. J.; LAWTON, J. H.. Beta diversity on geographic gradients in Britain. J. Anim. Ecol., v.61, p.151158, 1992.

HEPP, L. U.. Fauna de invertebrados aquáticos na bacia hidrográfica do rio Jacutinga, Jacutinga/RS. Dissertação (Mestrado em Ciências Biológicas) - Universidade Federal de Santa Maria, Santa Maria, 2005.

HIGUTI, J.. Fatores reguladores da biodiversidade de ostracoda (Crustacea) no vale aluvial do Alto Rio Paraná. Tese (Doutorado) - Universidade Estadual de Maringá, 2006.

HYNES, H. B. N.. The ecology of running waters. 3 ed. Toronto Press, 1970.

KALKMAN, V. J.; V. CLAUSNITZER, K. D. B.; DIJKSTRA; ORR, A G.; PAULSON, D. R.; VAN, J. T.. Global diversity of dragonflies (Odonata) in freshwater. Hydrobiologia, v.595, p.351-363, 2008.

KIKUCHI, R. M.; UIEDA, V. S.. Composição da comunidade de invertebrados de um ambiente lótico tropical e sua variação espacial e temporal. In: NESSIMIAN, J. L.; CARVALHO, A. L.. Ecologia de insetos aquáticos. Series Oecologia Brasiliensis, v.5. Rio de Janeiro: PPGE-UFRJ, 1998. p.157-173. 
LENAT, D. R.; PENROSE, D. L.; EAGLESON, K. W.. Variable effects of sediment addition on stream benthos.

Hydrobiologia, v.79, p.187-194, 1981.

LEWIS, O. T.. Climate changes, species-area curves and the extinction crisis. Philosophical Transactions of the Royal Society, v.361, p.163-171, 2006. DOI: http://10.1098/rstb.2005.1712

MARCO JR, P.; LATINI, A. O.. Estrutura de guildas e riqueza de espécies em uma comunidade de larvas de Anisoptera (Odonata) pp. 101-112. In: NESSIMIAN, J. L.; CARVALHO, A. L.. Ecologia de insetos aquáticos. Series Oecologia Brasiliensis, v.5. Rio de Janeiro: PPGE-UFRJ, 1998.

MARCO JR, P.; RESENDE, D. C.. Cues for Territory Choice in Two Tropical Dragonflies. Neotropical Entomology, v.33, n.4, p.397-401, 2004.

MANLY, B. F. J.. The statistics of natural selection. London Chapman \& Hall, 1985.

McCUNE, B.; MEFFORD, M. J.. PC-ORD: Multivariate Analysis of Ecological Data, Version 4. Gleneden Beach: MjM Software Design, 1999.

MAGURRAN, A. E.. Ecological diversity and its measurement. London: Chapman and Hall, 1988.

MERRITT, R. W.; CUMMINS K. W.. A introduction to the aquatic insects of North America. 2 ed. Dubuque: Kendall/Hunt Publishing Company, 1996.

MEYBECK, M.; FRIEDRICH, G.; THOMAS, R.; CHAPMAN, D.. River. In: CHAPMAN, D.. Water quality assessments: a guide to the use of biota, sediments, and water in environmental monitoring. E \& Fn Spon, 1996.

MINSHALL, G. W.. Aquatic insect-substratum relationships. In: RESH, V. H.; ROSENBERG, D. M.. The ecology of aquatic insects. New York: Praeger, 1984

MUGNAI, R.; NESSIMIAN, J. L.; BAPTISTA, D. F.. Manual de identificação de macroinvertebrados aquáticos do Estado do Rio de Janeiro. Rio de Janeiro: Technical Books, 2010.

NESSIMIAN, J. L.; DORVILLÉ, L. F. M.; SANSEVERINO, A. M.; BAPTISTA, D. F.. Relation between flood pulse and functional composition of the macroinvertebrate benthic fauna in the lower Rio Negro, Amazonas, Brazil. Amazoniana, v.15, p.3550, 1998.

ROBERTSON, A. L.; LANCASTER, J.; HILDREW, A. G.. Coarse particulate organic matter: A habitat or food resource for the meiofaunal community of a recently formed stream?. Arch. Hydrobiol, v.152, p.529-541, 2001.

SANTOS, T. C.; COSTA, J. M.; PEREIRA, S. M.; OLDRINI, B. B.. Estudo da distribuição da Odonatofauna (Insecta, Odonata) em trechos da bacia hidrográfica do rio Macacu (Cachoeiras de Macacu, RJ). In: CONGRESSO DE ECOLOGIA DO BRASIL, 7. Anais. São Paulo: Sociedade Brasileira de Ecologia, 2009.

SARRIQUET, P. E.; BORDENAVE, P.; MARMONIER, P.. Effects of bottom sediment restoration on interstitial habitat characteristics and benthic macroinvertebrate assemblages in a headwater stream. River research and applications, v.23, p.815-828, 2007

SCHNECK, F.; HEPP, L. U.. Fatores estruturadores de comunidades em riachos. Ciência \& Ambiente, v.41, p.5768,2010

SILVA, A. L. L.; ARCE, C. C. M.; CRISTALDO, P. F.; SANTOS, G. N.; NAKAGAKI, J. M.. Estudo Comparado da Diversidade Larval de Odonata (Insecta) presente nos Córregos Curral de Arame e Água Boa. Dourados, 2007.

SILVA, D.; MARCO JR, P.; RESENDE, D. C.. Adult odonate abundance and community assemblage measures as indicators of stream ecological integrity: A case study. Ecological Indicators, v.10, n.3, p.744-752, 2010. DOI: http://10.1016/j.ecolind.2009.12.004

STATZNER, B.; HIGLER, B.. Questions and comments on the River Continuum Concept. Canadian Journal of Fisheries and Aquatic Sciences, v.42, p.1038-1044, 1985.

SUHLING, F.. Temporal patterns of emergence of the riverine dragonfly Onychogomphus uncatus (Odonata: Gomphidae). Hydrobiologia, v.302, p.113-118, 1995.

SUHLING, F.; SCHENK, K.; PADEFFKE, T.; MARTENS, A.. A field study of larval development in a dragonfly assemblage in African desert ponds (Odonata). Hydrobiologia, v.528, n.1, p.75-85, 2004.

STEINBLUMS, I. J.; FROEHLICH, H. A.; LYONS, J. K.. Designing stable buffer strips for stream protection. Journal of Forestry, v.82, n.1, p.49-52, 1984.

TOWNSEND, C. R.. The patch dynamics concept of stream community ecology. Journal of the North American Benthological Society, v.8, p.36-50, 1989.

TREVISAN, A.; MALINOWSKI, R.; FRESCHI, M.; RAMBO, C.; GALIANO, D.; KÖNIG, R.; SELIVON, M.; RESTELLO, R.; HEPP, L. U.. Diversidade de Insetos Aquáticos do Lajeado Jupirangava, Ponte Preta/RS. Perspectiva (Erexim), Erechim, v. 28, n.101, p.103-110, 2004.

TUNDISI, J. G.; MATSUMURA-TUNDISI, T.. Limnologia. São Paulo: Oficina de Textos, 2008.

UIEDA, V. S.; GAJARDO, I. C. S. M.. Macroinvertebrados perifíticos encontrados em poções e corredeiras de um riacho. Naturalia, v.21, p.31-47, 1996

VANNOTE, R. L.; MINSHALL, G. W.; CUMMINGS, K. W.; SEDELL, J. R.; CUSHING, C. E.. The River Continuum Concept. Canadian Journal of Fisheries and Aquatic Sciences, v.37, p.130-137, 1980

VOS, M.; FLIK, B. J. G.; VIJVERBERG, J.; RINGELBERG, J.; MOOIJ, W. M.. From inducible defences to population dynamics: modelling refuge use and life history changes in Daphnia. Oikos, v.99, n.2, p.386-396, 2002.

WARD, J. V.. The four-dimensional nature of lotic ecosystems. Journal of the North American Benthological Society, v.8, n.1, p.2-8, 1989. 
WARD, J. V.. Aquatic insects ecology - 1: Biology and habitat. Journ. North Amer. Benthol. Socie., New York, v.11, n.3, p.8438, 1992.

WENTWORTH, C. K.. A scale of grade and class terms for clastic sediments. The Journ. Geol., v.30, p.377-392, 1922.

WESTFALL, M. J.; TENNESSEN, K. J.. Odonata, p.164Đ169. In: MERRITT, R. W.; CUMMINS, K. W.. An introduction to the aquatic insects of North America. 3 ed. Dubuque: Kendall Hunt Publishing, 1996.
WHEATON, W.. The Cyclic Behavior of The National Office Market, AREUEA Journal, v.15, n.4, p.281-299, 1987.

WHITTON, B. A.. River ecology. Oxford: Blackwell Scientific Publications, 1975.

WRIGHT, S.. Isolation by distance. Genetics, v.28, n.2, p.114138, 1943.

A CBPC - Companhia Brasileira de Produção Científica (CNPJ: 11.221.422/0001-03) detém os direitos materiais desta publicação. Os direitos referem-se à publicação do trabalho em qualquer parte do mundo, incluindo os direitos às renovações, expansões e disseminações da contribuição, bem como outros direitos subsidiários. Todos os trabalhos publicados eletronicamente poderão posteriormente ser publicados em coletâneas impressas sob coordenação da Sustenere Publishing, da Companhia Brasileira de Produção Científica e seus parceiros autorizados. Os (as) autores (as) preservam os direitos autorais, mas não têm permissão para a publicação da contribuição em outro meio, impresso ou digital, em português ou em tradução. 